\title{
Strategic Commitment to Price in a Supply Chain with Downstream Innovation
}

\author{
Xiaoxiao Chang, Fengping Shen \\ School of Economics and Management, Lanzhou University of Technology, Lanzhou, China \\ Email: changxiaox307@163.com
}

How to cite this paper: Chang, X.X. and Shen, F.P. (2019) Strategic Commitment to Price in a Supply Chain with Downstream Innovation. Open Journal of Business and Management, 7, 1690-1704. https://doi.org/10.4236/ojbm.2019.74117

Received: August 21, 2019

Accepted: September 16, 2019

Published: September 19, 2019

Copyright $\odot 2019$ by author(s) and Scientific Research Publishing Inc. This work is licensed under the Creative Commons Attribution International License (CC BY 4.0).

http://creativecommons.org/licenses/by/4.0/ (c) (1) Open Access

\begin{abstract}
We consider a supply chain with an upstream supplier and a downstream manufacturer who invests in innovation. We present an analytical framework for innovation decisions in a centralized, a flexible price and a commitment to price. These results show that the innovation by commitment to price is still insufficient and the supplier remains flexible price beyond a threshold amount of demand uncertainty. To solve this problem, we propose a combination mechanism, which consists of a commitment to price, a cost sharing and a compensation for the risk of demand uncertainty. We study the impact of combination mechanism with endogenous downstream innovation. Our research results show that the innovation by combination mechanism may be greater than or equal to the one by a centralized. More importantly than all of that, the combination mechanism can improve the performance of the supply chain and ensure that both supply chain members achieve a win-win situation.
\end{abstract}

\section{Keywords}

Supply Chain, Innovation, Commitment to Price, Cost Sharing, Risk Compensation

\section{Introduction}

The excessive use of natural resources occasioned by rapid economic growth has damaged the environment and raised many environmental concerns [1] [2]. To conserve energy and reduce carbon emissions, many countries have established environmental regulations. To conform to the new environmental regulations, companies have had to adopt environmentally friendly practices. The innovation has been one of the important ways that companies have dealt with environmental issues [3]. The innovation can encourage sustainable use of products and 
services, or facilitate wider adoption of new environmentally friendly technologies [4] [5]. Plambeck (2013) [6] describes five "cleantech" firms (ZETA, First Solar, Better Place, Amyris, and Calera) and calls for guidelines on how the operations management community can stimulate innovation that promotes environmental sustainability. Innovation is one of the key drivers in the creation of high-technology products. These days, firms rely less on internal resources that they control directly. Specifically, the innovative technology offerings of some firms often come with economic characteristics (scale-cost functions, risk profiles, cash flow profiles, etc.) that are drastically different from the traditional technologies that they substitute [7]. Major suppliers in innovative industries, such as AMD and Intel, rely on their downstream manufacturers' innovation and investment efforts for their own success and growth, for example, the partnership between Toshiba and Sony in which Toshiba provides customized integrated circuits for the Playstation 2 product. Hence, in this paper we focus on an innovative supply chain that consists of a supplier and a manufacturer. The manufacturer has an opportunity to invest in innovation that will either enhance demand for its product or reduce its marginal production costs.

Our paper is broadly related to the incentives in supply chains for investments in innovation. Zhu et al. (2007) [8] study manufacturer efforts in encouraging upstream innovation investment efforts. Their analyses reveal that at most one party needs to make innovation unless there are resource constraints. That is, a firm's investment in its supplier's innovation often frees the other from making any investment. Bhaskaran and Krishnan (2009) [9] examine revenue sharing, investment cost sharing and innovation effort sharing contracts in collaborating new product development, and show that for projects with substantial timing uncertainty, investment sharing works better, whereas for projects with quality uncertainty, innovation sharing tends to be more attractive under certain conditions. Yao et al. (2011) [10] use a principal-agent model to study the manufacturers' problem in inducing suppliers to adopt new technologies, focusing on unobservable adoption costs and investment. Wang and Shin (2015) [11] consider a supply chain with a manufacturer and an upstream supplier. The supplier invests in innovation, which increases the value of the product to consumers, and the manufacturer sets the product price and sells to consumers. They study the impact of different contracts on innovation by focusing on three types of contracts: 1) the wholesale price contract, 2) the quality-dependent wholesale price contract, and 3) the revenue-sharing contract.

Different from above these literatures, we study the innovation investment decision by the downstream manufacturer, instead of the upstream supplier. Several other papers also incorporate downstream innovation. Gilbert and Cvsa (2003) [12] examine mechanisms that stimulate downstream innovation in a supply chain. They analyze the effect of price commitment by the upstream supplier. It is important to point out that our paper uses the framework of Gilbert and Cvsa's research to examine the interactions between price and innovation, but one of the key features of our paper is that it provides a combination me- 
chanism base on their research. Liu and Cui (2010) [13] examine a manufacturer's optimal decisions on extending its product line when the manufacturer sells through either a centralized channel or a decentralized channel. They show that a manufacturer may provide a longer product line for consumers in a decentralized channel than in a centralized channel if the market is fully covered. Salvador and Villena (2013) [14] analyze the impact of supplier involvement on technical performance of new products. Supplier integration has been largely found to be related to product development performance $(2002,2005,2007,2007)$ [15] [16] [17] [18]. Adelman et al. (2014) [19] take the upstream firm's point of view. They address the question of when and how an upstream firm can encourage its customers to improve their products and charge customers a premium.

We find that the above studies have made important contributions to the innovation in a supply chain, and we benefit a great deal from them. We think some inadequacies should be focused on. For instance, there is little research on what can a supplier do to motivate the downstream manufacturer to invest more in innovation and increase own profit. Meanwhile, how can a supplier gain more profits from the manufacturer's higher innovation investment? To fill the gap, we design a combination mechanism and analyze the impacts of the combination mechanism to the supplier, the manufacturer and the total supply chain.

More specifically, we address the following research questions:

1) What are the differences of the innovation decision between a centralized and a decentralized supply chain, respectively?

2) How and when can an upstream supplier encourage its downstream manufacturer to invest in innovation while still being able to recoup the benefits of doing so?

This paper is organized as follows. Section 2 introduces the notations and assumptions for the supplier and the manufacturer in the model. Section 3 introduces the model and analyzes the three cases. By comparing the innovation of different cases, we provide our combination mechanism and the answers to our research questions in Section 4. We conclude the results and suggest topics for future research in Section 5. All proofs of this paper are in the appendices.

\section{Model Notations and Assumptions}

\subsection{Notations}

We use the following notations in this paper: $w$ is the wholesale price that the manufacturer purchases his component supply from the supplier; $p$ is the sell price of product; $q$ is the order quantity; $\theta$ denotes the degree of innovation; the subscript " $m$ ", " $\mathrm{r}$ ", " $\mathrm{T}$ ", " $\mathrm{c}$ " means the parameters corresponding to the manufacturer, the retailer, the total supply chain system and the centralized system; the superscript "FP", "CP", "CM" means the parameters corresponding to the flexible price, the commitment to price and the combination mechanism.

\subsection{Assumptions}

Utilizing the model framework and analysis in Gilbert and Cvsa (2003), we make 
five basic assumptions for the model as follows:

Assumption 1.

We adopt the convention of using the pronouns she and he to refer to the supplier and the manufacturer respectively throughout this paper.

Assumption 2.

The information about each player's demand distribution, cost structure, and decision rules are common knowledge to all the parties concerned.

Assumption 3.

Without loss of generality, we normalize the supplier's and manufacturer's actual production cost to zero.

Assumption 4.

Let $r$ be the maximum amount of cost reduction that can be attained via the manufacturer's innovation. Thus, the manufacturer can reduce his marginal costs by $r \theta$. In practice, we can use a strictly convex cost function $c(\theta)$ to depict the investment of the manufacturer's innovation. That is, the cost for providing the services has the properties of $\mathrm{d} c(\theta) / \mathrm{d} \theta>0$ and $\mathrm{d}^{2} c(\theta) / \mathrm{d} \theta^{2}>0$. One form commonly adopted in literature [12] is given:

$$
c(\theta)=I \theta^{2}
$$

To avoid trivial problems, we require that it not be too cheap to reduce costs, it is necessary to impose additional inequality constraint on the parameters $2 I>r^{2}$.

Assumption 5.

To model the base-case demand in the market that is served by the manufacturer, let us assume that the inverse demand function is linear in the quantity produced, and define the market clearing price as follows:

$$
p=a-q
$$

where $a$ is the primary demand (i.e., potential demand if the goods are free of charge), in order to demonstrate the uncertainty in market demand that results from changes in economic and business conditions, we assume that $a$ is a random variable, as follows:

$$
a=\bar{a}+\varepsilon
$$

Here, $\bar{a}$ is the mean of the potential demand, and $\varepsilon$ is an additive error term, follows a normal distribution such that $E(\varepsilon)=0$ and $\operatorname{Var}(\varepsilon)=\sigma^{2}$.

By above notations and assumptions, the supplier's profit and the manufacturer's profit are determined by

$$
\begin{gathered}
\pi_{s}=w q \\
\pi_{m}=(p-w+r \theta) q-I \theta^{2}
\end{gathered}
$$

If the supply chain is vertically integrated, then the profit of the centralized supply chain is

$$
\pi_{c}=(p+r \theta) q-I \theta^{2}
$$




\section{Benchmark Models}

\subsection{Centralized Case}

It is obvious that the supply chain will perform best if the channel is centrally controlled. Since the wholesale price is only used to divide the profit between the supplier and the manufacturer, $w$ is no longer decision variable in the centralized supply chain. The decision variables are only $\theta$ and $q$. In this case, the centralized firm moves first by determining the $\theta$ of the maximum cost reduction in which to invest, and responds by choosing a quantity when the demand is observed.

Substituting (2) and (3) into (6), we obtain:

$$
\pi_{c}=(\bar{a}+\varepsilon-q+r \theta) q-I \theta^{2}
$$

Proposition 1.

In a centralized supply chain, the optimal expected amount of innovation and order quantity are given by

$$
\begin{gathered}
E\left(\theta_{c}\right)=\frac{\bar{a} r}{4 I-r^{2}} \\
E\left(q_{c}\right)=\frac{2 \bar{a} I}{4 I-r^{2}}
\end{gathered}
$$

All of the proofs of the proposition, lemma and corollary in this paper are given in the Appendix.

From Proposition 1, we can get the expected profits of the centralized case:

$$
E\left(\pi_{c}\right)=\frac{\bar{a}^{2} I}{4 I-r^{2}}+\frac{\sigma^{2}}{4}
$$

\subsection{Flexible Price Case}

In this section, we model the decision process as a sequential, the leader-follower game: the manufacturer moves first by determining the $\theta$ of the maximum cost reduction in which to invest, and responds by choosing a quantity when the demand is observed. After demand is observed, the supplier reacts to both demand and the effect of the manufacturer's innovation by announcing a wholesale price. Finally, the manufacturer responds by choosing a quantity. The following lemma 1 summarizes and presents equilibrium under the flexible price by Gilbert and Cvsa, 2003.

Lemma 1.

The optimal decisions and expected profits of the supplier and the manufacturer under the flexible price are presented by

$$
\begin{aligned}
& E\left(\theta^{F P}\right)=\frac{\bar{a} r}{16 I-r^{2}} \\
& E\left(w^{F P}\right)=\frac{8 \bar{a} I}{16 I-r^{2}} \\
& E\left(q^{F P}\right)=\frac{4 \bar{a} I}{16 I-r^{2}}
\end{aligned}
$$




$$
\begin{gathered}
E\left(\pi_{s}^{F P}\right)=\frac{32 \bar{a}^{2} I^{2}}{\left(16 I-r^{2}\right)^{2}}+\frac{\sigma^{2}}{8} \\
E\left(\pi_{m}^{F P}\right)=\frac{\bar{a}^{2} I}{16 I-r^{2}}+\frac{\sigma^{2}}{16}
\end{gathered}
$$

\subsection{Commitment to Price Case}

In this section, we investigate the situation in which the supplier commits to a wholesale price in advance of the manufacturer's investment and the realization of demand. We model this as the following leader-follower game: While demand uncertainty remains unresolved, the supplier acts as a leader by committing to a wholesale price that is not contingent upon either demand or the investment of the downstream manufacturer, and the manufacturer responds by determining $\theta$, the fraction of the maximum cost reduction, in which to invest. Finally, the manufacturer makes a quantity decision when demand information is revealed. The following lemma 2 summarizes and presents equilibrium the player's decisions and profits under the commitment to price by Gilbert and Cvsa, 2003.

Lemma 2.

The optimal decisions and expected profits of the supplier and the manufacturer under the commitment to price are presented by

$$
\begin{gathered}
E\left(\theta^{C P}\right)=\frac{\bar{a} r}{2\left(4 I-r^{2}\right)} \\
E\left(w^{C P}\right)=\frac{\bar{a}}{2} \\
E\left(q^{C P}\right)=\frac{\bar{a} I}{4 I-r^{2}} \\
E\left(\pi_{s}^{C P}\right)=\frac{\bar{a}^{2} I}{2\left(4 I-r^{2}\right)} \\
E\left(\pi_{m}^{C P}\right)=\frac{\bar{a}^{2} I}{4\left(4 I-r^{2}\right)}+\frac{\sigma^{2}}{4}
\end{gathered}
$$

\subsection{Comparative Analysis}

By comparing (13) and (18), we can see that $E\left(\theta^{C P}\right)>E\left(\theta^{F P}\right)$, this shows that the supplier's commitment to price results in more innovation by the manufacturer. In view of this, we will only focus on the innovation of the centralized case and the commitment to price.

Proposition 2.

$$
E\left(\theta_{c}\right)=2 E\left(\theta^{C P}\right)
$$

Proposition 2 shows that the innovation is still insufficient under the commitment to price, because only half of the innovation is invested. 
Furthermore, by Proposition 1 in Gilbert and Cvsa 2003, we can see that the expected profits of the manufacturer's and the total supply chain are always larger if the supplier commits in advance to a wholesale price than if he remains flexible. However, the supplier's profits are higher if she retains pricing flexibility when it is characterized by large amounts of demand uncertainty.

Synthesizes the above analysis, we can find that the commitment to price has at least two limitations. One is that the innovation is still insufficient. Another is that the supplier would not like to provide this contract. This means that a fundamental question still remains unanswered. Can the incentives of the supplier and the manufacturer be aligned through a contract so that the manufacturer is willing to invest his innovation equal to the innovation of the centralized case? We address this issue in the next section.

\section{Combination Mechanism}

Through the previous analysis of the commitment to price, we propose a new combination mechanism, which consists of a commitment to price, a cost sharing and a compensation for the risk of demand uncertainty. Specifically, in this contract, the supplier first sets a wholesale price $w$ and shares a proportion $t(0 \leq t \leq 1)$ for the investment of the manufacturer's innovation. Furthermore, the supplier gets a compensation $\lambda \sigma^{2}(\lambda \geq 0)$ for the risk of demand uncertainty from the manufacturer. As a result, the manufacturer can obtain more revenue and saves more cost, which then provides this with an incentive to invest more in innovation. After observing $w$ and $t$, the manufacturer invests in innovation. Finally, the manufacturer sets the quantity when demand is revealed.

In above combination mechanism, the supplier's profit and the manufacturer's profit are determined by

$$
\begin{gathered}
\pi_{s}^{C M}=w q-t I \theta^{2}+\lambda \sigma^{2} \\
\pi_{m}^{C M}=(p-w+r \theta) q-(1-t) I \theta^{2}-\lambda \sigma^{2}
\end{gathered}
$$

The following Proposition describes equilibrium of the player's decisions and profits under the combination mechanism.

Proposition 3.

In a combination mechanism $(w, t, \lambda)$, if the $0 \leq t<1-\frac{r^{2}}{4 I}$, the optimal decisions and expected profits of the supplier and the manufacturer are presented by

$$
\begin{gathered}
E\left(\theta^{C M}\right)=\frac{(1-t) \bar{a} r}{8(1-t)^{2} I-(2-3 t) r^{2}} \\
E\left(w^{C M}\right)=\frac{\left(4(1-t)^{2} I-(1-2 t) r^{2}\right) \bar{a}}{8(1-t)^{2} I-(2-3 t) r^{2}} \\
E\left(q^{C M}\right)=\frac{2(1-t)^{2} \bar{a} I}{8(1-t)^{2} I-(2-3 t) r^{2}}
\end{gathered}
$$




$$
\begin{gathered}
E\left(\pi_{s}^{C M}\right)=\frac{(1-t)^{2} \bar{a}^{2} I}{8(1-t)^{2} I-(2-3 t) r^{2}}+\lambda \sigma^{2} \\
E\left(\pi_{m}^{C M}\right)=\frac{(1-t)^{3}\left(4(1-t) I-r^{2}\right) \bar{a}^{2} I}{\left(8(1-t)^{2} I-(2-3 t) r^{2}\right)^{2}}+\frac{(1-4 \lambda) \sigma^{2}}{4}
\end{gathered}
$$

Proposition 3 implies that the supplier would not agree with the combination mechanism when the proportion of cost sharing is high $\left(1-\frac{r^{2}}{4 I} \leq t \leq 1\right)$, mainly because of if the $\lambda=0$, the supplier unprofitable in this condition. Furthermore, if $t=0$ and $\lambda=0$ in Proposition 3, we can get results which is the same as the single commits to price. Thus, Proposition 3 shows that the combination mechanism is much better availability than the single commits to price.

From Proposition 3, we have Corollary 1, Corollary 2 and Corollary 3, as follows:

Corollary 1.

With the combination mechanism,

i) for all $0<t<1-\frac{r^{2}}{4 I}, E\left(\theta^{C M}\right)>E\left(\theta^{C P}\right)$;

ii) when $0 \leq t<\frac{1}{2}$, then $E\left(\theta^{C M}\right)<E\left(\theta_{c}\right)$;

iii) when $t=\frac{1}{2}$, then $E\left(\theta^{C M}\right)=E\left(\theta_{c}\right)$;

iv) when $\frac{1}{2}<t<1-\frac{r^{2}}{4 I}$, then $E\left(\theta^{C M}\right)>E\left(\theta_{c}\right)$.

Corollary 1 shows that the innovation under the combination mechanism is high as compare to the innovation under the commitment to price. Furthermore, if the supplier shares half the investment of the downstream innovation, the combination mechanism can incentive the manufacturer to enhance an innovation, which is equal to the innovation of the centralized case. Especially when the sharing cost is high $\left(\frac{1}{2}<t<1-\frac{r^{2}}{4 I}\right)$, the manufacturer would like to over-innovation.

Corollary 2.

With the combination mechanism,

i) when $0<t<\frac{1}{2}$, then $E\left(q^{C M}\right)>E\left(\theta^{C P}\right)$;

ii) when $t=\frac{1}{2}$, then $E\left(q^{C M}\right)=E\left(q^{C P}\right)$;

iii) when $\frac{1}{2}<t<1-\frac{r^{2}}{4 I}$, then $E\left(q^{C M}\right)<E\left(q^{C P}\right)$;

iv) for all $0 \leq t<1-\frac{r^{2}}{4 I}, E\left(q^{C M}\right)>E\left(q^{C}\right)$;

Corollary 2 shows that the order quantity is identical with the commitment to price when the innovation is sufficient under the combination mechanism. When the manufacturer makes an over-innovation under the combination me- 
chanism, however, the order quantity is less than the commitment to price. We can see that the order quantity of the combination mechanism is less than the centralized case by Corollary 2, and the reason of this result is that the whole price is endogenous in the combination mechanism.

Corollary 3.

With the combination mechanism,

i) The existence and uniqueness of $\bar{t} \in\left(0,1-\frac{r^{2}}{4 I}\right)$ makes the maximization of the total supply chain;

ii) for a given $t \in(0, \bar{t})$, the expected profits of the total supply chain increases in $t$,

iii) for a given $t \in\left(\bar{t}, 1-\frac{r^{2}}{4 I}\right)$, the expected profits of the total supply chain decreases in $t$.

From Corollary 3 and Lemma 2, we have Corollary 4.

Corollary 4.

i) The existence and uniqueness of $\hat{t} \in\left(\bar{t}, 1-\frac{r^{2}}{4 I}\right)$ makes $E\left(\pi_{T}^{C M}\right)=E\left(\pi_{T}^{C P}\right)$.

ii) when $t \in(0, \hat{t}), E\left(\pi_{T}^{C M}\right)>E\left(\pi_{T}^{C P}\right)$.

Corollary 4 shows that the supply chain performance of the combination mechanism is better than the commitment to price when the supplier provides a low cost sharing.

According to the above comprehensive analysis and the Proposition 1 of the reference [12], we can find that the players of the supply chain are easier to produce win-win situations under the combination mechanism. To better understand our results, we make a numerical example further. We assume that $\bar{a}=100, \quad I=4, \quad r=1, \sigma^{2}=500 \Delta \pi_{s}=E\left(\pi_{s}^{C M}\right)-E\left(\pi_{s}^{F P}\right)$ and $\Delta \pi_{m}=E\left(\pi_{m}^{C M}\right)-E\left(\pi_{m}^{F P}\right)$, so we can get Observation 1 and Observation 2 .

Observation 1 .

For a given $t=0.15$, if $0.03<\lambda<0.23$, then $\Delta \pi_{m}>0$ and $\Delta \pi_{r}>0$.

Observation 2.

For a given $\lambda=0.1$, if $0 \leq t<0.55$, then $\Delta \pi_{m}>0$ and $\Delta \pi_{r}>0$.

Observation 1 and Observation 2 show that the supplier and the manufacturer can achieve a win-win situation by combination mechanism.

\section{Conclusions}

In this paper, we develop a framework to study the strategic roles of the commitment to price in a supply chain with downstream innovation. We examine the optimal decisions for innovation in centralized, flexible price and commitment to price. Furthermore, we provide a combination mechanism to improve the performance or to achieve a win-win the players of supply chain.

We have some new findings that are different from earlier studies. We find that the innovation is also insufficient in the commitment to price and the in- 
vestment of this innovation is merely half of the one in centralized. Our results show that the combination mechanism has a great impact on the innovation of both manufacturers and retailers, and the innovational effect is different for different cost sharing of the combination mechanism; it may have under-innovation, effective innovation and over-innovation. Our results also show that the supply chain performance of the combination mechanism is better than the one of the single commitment to price when the supplier provides a low cost sharing. At the same time, our numerical examples also show that the members of supply chain can achieve a win-win situation in combination mechanism no matter how the demand uncertainty.

Our findings provide some guidance to managers of suppliers on how to encourage their manufacturers to invest more in innovation, and simultaneously gain more profit.

The main limitation of this paper concerns the assumption that all of the players in the supply chain have access to the same information. However, it is an ideal situation because of the information asymmetry in the market. In future research, a number of assumptions in this paper can be relaxed. We focus on the impact of contracts on downstream innovation in a supply chain in this paper. However, in some cases, the supplier can also invest to improve the quality of the component. Incorporating the upstream component innovation decision as well as the downstream one can engender several new interesting research questions. However, these are beyond the scope of our paper, and we leave them for future research.

\section{Conflicts of Interest}

The authors declare no conflicts of interest regarding the publication of this paper.

\section{References}

[1] Qi, G.Y., Shen, L.Y., Zeng, S.X. and Jorge, O.J. (2010) The Drivers for Contractors' Green Innovation: An Industry Perspective. Journal of Cleaner Production, 18, 1358-1365.

[2] Panwar, N., Kaushik, S. and Kothari, S. (2011) Role of Renewable Energy Sources in Environmental Protection: A Review. Renewable and Sustainable Energy Reviews, 15, 1513-1524. https://doi.org/10.1016/j.rser.2010.11.037

[3] Weng, H.H., Chen, J.S. and Chen, P.J. (2015) Effects of Green Innovation on Environmental and Corporate Performance: A Stakeholder Perspective. Sustainability, 7, 4997-5026. https://doi.org/10.3390/su7054997

[4] Girotra, K. and Netessine, S. (2013) OM-Forum Business Model Innovation for Sustainability. Manufacturing \& Service Operations Management, 15, 537-544. https://doi.org/10.1287/msom.2013.0451

[5] Pässilä, P., Pulkka, L. and Junnila, S. (2015) How to Succeed in Low-Energy Housing-Path Creation Analysis of Low-Energy Innovation Projects. Sustainability, 7, 8801-8822. https://doi.org/10.3390/su7078801

[6] Plambeck, E.L. (2013) OM Forum-Operations Management Challenges for Some 
“Cleantech" Firms. Manufacturing \& Service Operations Management, 15, 527-536. https://doi.org/10.1287/msom.2013.0455

[7] Teece, D.J. (2010) Business Models, Business Strategy and Innovation. Long Range Planning, 43, 172-194. https://doi.org/10.1016/j.lrp.2009.07.003

[8] Zhu, K., Zhang, R.Q. and Tsung, F. (2007) Pushing Quality Improvement along Supply Chains. Management Science, 53, 421-436. https://doi.org/10.1287/mnsc.1060.0634

[9] Bhaskaran, S.R. and Krishnan, V. (2009) Effort, Revenue, and Cost Sharing Mechanisms for Collaborative New Product Development. Management Science, 55, 1152-1169. https://doi.org/10.1287/mnsc.1090.1010

[10] Yao, T., Feng, B. and Jiang, B. (2011) Incentive Contracts for Technology Adoption within a Supply Chain: A Principal-Agent Perspective. Working Paper, Pennsylvania State University, University Park, PA.

[11] Wang, J.Q. and Shin, H.D. (2015) The Impact of Contracts and Competition on Upstream Innovation in a Supply Chain. Production and Operations Management, 24, 134-146. https://doi.org/10.1111/poms.12218

[12] Gilbert, S.M. and Cvsa, V. (2003) Strategic Commitment to Price to Stimulate Downstream Innovation in a Supply Chain. European Journal of Operational Research, 150, 617-639. https://doi.org/10.1016/S0377-2217(02)00590-8

[13] Liu, Y. and Cui, T.H. (2010) The Length of Product Line in Distribution Channels. Marketing Science, 29, 474-482. https://doi.org/10.1287/mksc.1090.0533

[14] Salvador, F. and Villena, V.H. (2013) Supplier Integration and NPD Outcomes: Conditional Moderation Effects of Modular Design Competence. Journal of Supply Chain Management, 49, 87-113. https://doi.org/10.1111/j.1745-493x.2012.03275.x

[15] Ragatz, G.L., Handfield, R.B. and Petersen, K.J. (2002) Benefits Associated with Supplier Integration into New Product Development under Conditions of Technological Uncertainty. Journal of Business Research, 55, 389-400. https://doi.org/10.1016/S0148-2963(00)00158-2

[16] Petersen, K.J., Handfield, R.B. and Ragatz, G.L. (2005) Supplier Integration into New Product Development: Coordinating Product, Process and Supply Chain Design. Journal of Operations Management, 23, 371-388. https://doi.org/10.1016/j.jom.2004.07.009

[17] Koufteros, X., Cheng, T.C. and Lai, K. (2007) "Black-Box" and "Gray-Box" Supplier Integration in NPD: Antecedents, Consequences and the Moderating Role of Firm Size. Journal of Operations Management, 25, 847-870. https://doi.org/10.1016/j.jom.2006.10.009

[18] Humphreys, P., Huang, G., Cadden, T. and McIvor, R. (2007) Integrating Design Metrics within the Early Supplier Selection Process. Journal of Purchasing and Supply Management, 13, 42-52. https://doi.org/10.1016/j.pursup.2007.03.006

[19] Adelman, D., Aydin, A. and Parker R. (2014) Driving Technology Innovation down a Competitive Supply Chain. Working Paper, the University of Chicago Booth School of Business, Chicago, IL. 


\section{Appendix}

The author declares no conflicts of interest regarding the publication of this paper.

\section{Proof of Proposition 1}

Obviously, $\pi_{c}$ is a concave quadratic function of $q$, using the first-order condition, we get

$$
q_{c}(\theta)=\frac{a+r \theta}{2}
$$

Substituting (A1) into (7), we have

$$
E\left(\pi_{c}(\theta)\right)=\frac{(\bar{a}+r \theta)^{2}+\sigma^{2}}{4}-I \theta^{2}
$$

$E\left(\pi_{c}(\theta)\right)$ is a concave quadratic function of $\theta$, using the first-order condition, we get (8). Substituting (8) into (10), we have (9).

Proof of Lemma 1

Obviously, $\pi_{m}$ is concave in $q$, using the first-order condition, we get

$$
q_{F P}(w, \theta)=\frac{a+\varepsilon-w+r \theta}{2}
$$

Substituting (A3) into (4) and using the first-order condition in $w$, we get

$$
w_{F P}(\theta)=\frac{a+\varepsilon+r \theta}{2}
$$

Substituting (A3) and (A4) into (5), we have

$$
E\left(\pi_{m}(\theta)\right)=\frac{(\bar{a}+r \theta)^{2}+\sigma^{2}}{16}-I \theta^{2}
$$

$E\left(\pi_{m}(\theta)\right)$ is a concave quadratic function of $\theta$, using the first-order condition, we get

(11). Substituting (11) into (A3) and (A4), we have (13) and (12). Then substituting (11), (12) and (13) into (4) and (5), we have (14) and (15).

Proof of Lemma 2

It is easy to prove Lemma 2 by the method similar to Lemma 1, so we omit it.

Proof of Proposition 2

From (8) and (16), it is easy to see this proposition holds.

Proof of Proposition 3

Substituting (2) into (21), it can be found that $\pi_{m}^{C M}$ is a concave quadratic function of $q$, using the first-order condition, we get

$$
q^{C M}(\theta, w)=\frac{a+r \theta-w}{2}
$$

Substituting (A6) into (21), we have

$$
E\left(\pi_{m}^{C M}(\theta, w)\right)=\frac{(\bar{a}+r \theta-w)^{2}}{4}-(1-t) I \theta^{2}+\frac{(1-4 \lambda) \sigma^{2}}{4}
$$

From (A7), we can find that $E\left(\pi_{c}(\theta, w)\right)$ is a concave quadratic function of 
$\theta$ when $t$ satisfies $0 \leq t<1-\frac{r^{2}}{4 I}$. Using the first-order condition, we get:

$$
\theta^{C M}(w)=\frac{(\bar{a}-w) r}{4(1-t) I-r^{2}}
$$

Substituting (A6) and (A8) into (22), we have:

$$
E\left(\pi_{s}^{C M}(w)\right)=-\frac{(\bar{a}-w)\left(t \bar{a} r^{2}-\left(8(1-t)^{2} I-(2-3 t) r^{2}\right) w\right) I}{\left(4(1-t) I-r^{2}\right)^{2}}+\lambda \sigma^{2}
$$

It can be inferred from $0 \leq t<1-\frac{r^{2}}{4 I}$ that $8(1-t)^{2} I-(2-3 t) r^{2}>0$. Thus, $E\left(\pi_{s}^{C M}(w)\right)$ is a concave quadratic function of $w$. Using the first-order condition, we get (24). Substituting (24) into (A7), we have (23); Substituting (23) and (24) into (A6), we have (25); and then we obtain (26) and (27).

Proof of Corollary 1

From (16) and (23), we get:

$$
E\left(\theta^{C M}\right)-E\left(\theta^{C P}\right)=\frac{\left(8(1-t)^{2} I-r^{2}\right) t \bar{a} r}{2\left(8(1-t)^{2} I-(2-3 t) r^{2}\right)\left(4(1-t) I-r^{2}\right)}
$$

From (A10), we obtain (i).

From (8) and (23), we get:

$$
E\left(\theta^{C M}\right)-E\left(\theta_{c}\right)=-\frac{(1-2 t)\left(4(1-t) I-r^{2}\right) \bar{a} r}{\left(8(1-t)^{2} I-(2-3 t) r^{2}\right)\left(4 I-r^{2}\right)}
$$

Due to $2 I \geq r^{2}$, so $1-\frac{r^{2}}{4 I}>\frac{1}{2}$, from (A11), we obtain (ii), (iii) and (iv).

Thus, Corollary 1 is proved.

Proof of Corollary 2

From (18) and (25), we get:

$$
E\left(q^{C M}\right)-E\left(q^{C P}\right)=\frac{(1-2 t) t \bar{a} I}{\left(8(1-t)^{2} I-(2-3 t) r^{2}\right)\left(4 I-r^{2}\right)}
$$

From (A12), we obtain (i), (ii) and (iii).

Furthermore, from (9) and (25), we have:

$$
E\left(q^{C M}\right)-E\left(q^{C}\right)=-\frac{2\left(4(1-t)^{2} I-r^{2}+(1+t) t r^{2}\right) \bar{a} I}{\left(8(1-t)^{2} I-(2-3 t) r^{2}\right)\left(4 I-r^{2}\right)}
$$

From (10), we can see that $E\left(q^{C M}\right)-E\left(q^{C}\right)<0$, so (iv) is tenable.

Thus, Corollary 2 is proved.

Proof of Corollary 3

From (26) and (27), we have:

$$
E\left(\pi_{T}^{C M}\right)=\frac{(1-t)^{2}\left(12(1-t)^{2} I-(3-4 t) r^{2}\right) \bar{a}^{2} I}{\left(8(1-t)^{2} I-(2-3 t) r^{2}\right)^{2}}+\frac{\sigma^{2}}{4}
$$


By the first derivative of $t$ for (A14), we obtain:

$$
\frac{\mathrm{d} E\left(\pi_{T}^{C M}\right)}{\mathrm{d} t}=-\frac{2(1-t) f_{1}(t) \bar{a}^{2} I r^{2}}{\left(8(1-t)^{2} I-(2-3 t) r^{2}\right)^{3}}
$$

Here, $f_{1}(t)=4(1-t)^{2}(5 t-1) I+\left(6 t^{2}-6 t+1\right) r^{2}$. By the first derivative of $t$ for $f_{1}(t)$, we get $f_{1}^{\prime}(t)=4(1-t)(7-15 t) I-6(1-2 t) r^{2}$. Furthermore, we can get two solutions of $f_{1}^{\prime}(t)=0$, which are $t_{1}=\frac{\left(3 r^{2}-22 I-\sqrt{2 I\left(32 I-21 r^{2}\right)+9 r^{4}}\right) I}{30}$ and $t_{2}=\frac{\left(3 r^{2}-22 I+\sqrt{2 I\left(32 I-21 r^{2}\right)+9 r^{4}}\right) I}{30}$. We can easy prove that $\frac{1}{5}<t_{1}<\frac{1}{2}$ and $1-\frac{r^{2}}{4 I}<t_{2}<1$, so $f_{1}^{\prime}(t)>0$ when $t \in\left(0, t_{1}\right)$, and $f_{1}^{\prime}(t)<0$ when $t \in\left(t_{1}, 1-\frac{r^{2}}{4 I}\right)$. Due to $f_{1}(0)=-4 I+r^{2}<0, \quad f_{1}\left(\frac{1}{5}\right)=\frac{r^{2}}{25}>0$, $f_{1}\left(1-\frac{r^{2}}{4 I}\right)=\frac{\left(4 I-r^{2}\right)^{2} r^{2}}{16 I}>0$ and $f_{1}(t)$ and $E\left(\pi_{T}^{C M}\right)$ are a continuous function in the $\left[0,1-\frac{r^{2}}{4 I}\right]$, so we can deduced that the existence and uniqueness of $\bar{t} \in\left(0,1-\frac{r^{2}}{4 I}\right)$ makes $f_{1}(\bar{t})=0$, and $\frac{\mathrm{d} E\left(\pi_{T}^{C M}\right)}{\mathrm{d} t}>0$ when $t \in(0, \bar{t})$, and $\frac{\mathrm{d} E\left(\pi_{T}^{C M}\right)}{\mathrm{d} t}<0$ when $t \in\left(\bar{t}, 1-\frac{r^{2}}{4 I}\right)$. Furthermore, by the first derivative of t for (40), we can easy prove that $\frac{\mathrm{d}^{2} E\left(\pi_{T}^{C M}\right)}{\mathrm{d} t^{2}}<0$ when $t=\bar{t}$. Thus, the existence and uniqueness of $\bar{t} \in\left(0,1-\frac{r^{2}}{4 I}\right)$ makes the maximization of the total supply chain with the combination mechanism. i.e. Corollary 3 is proved.

Proof of Corollary 4

From (19), (20), (26) and (27), we have:

$$
\begin{aligned}
E\left(\Delta \pi_{T}\right) & =E\left(\pi_{T}^{C M}\right)-E\left(\pi_{T}^{C P}\right) \\
& =\frac{(1-t)^{2}\left(16(1-3 t)(1-t)^{2} I-\left(4+16 t^{2}-17 t\right) r^{2}\right) \bar{a}^{2} r^{2} I t}{4\left(8(1-t)^{2} I-(2-3 t) r^{2}\right)^{2}\left(4 I-r^{2}\right)}
\end{aligned}
$$

By the first derivative of $t$ for (A16), we obtain:

$$
\frac{\mathrm{d} E\left(\Delta \pi_{T}\right)}{\mathrm{d} t}=-\frac{2(1-t) f_{1}(t) \bar{a}^{2} I r^{2}}{\left(8(1-t)^{2} I-(2-3 t) r^{2}\right)^{3}}
$$

Here, $\frac{\mathrm{d} E\left(\Delta \pi_{T}\right)}{\mathrm{d} t}=\frac{\mathrm{d} E\left(\pi_{T}^{C M}\right)}{\mathrm{d} t}$. According to proof of Corollary 3 , it is easy to 
prove that $t=\bar{t}$ makes the maximization of $E\left(\Delta \pi_{T}\right)$. Furthermore, we can see $E\left(\Delta \pi_{T}\right)<0$ when $t=1-\frac{r^{2}}{4 I}$. So, the existence and uniqueness of $\hat{t} \in\left(\bar{t}, 1-\frac{r^{2}}{4 I}\right)$ makes $E\left(\Delta \pi_{T}\right)=0$ that $E\left(\pi_{T}^{C M}\right)=E\left(\pi_{T}^{C P}\right)$ and $t \in(0, \hat{t})$ makes $E\left(\Delta \pi_{T}\right)>0$ that $E\left(\pi_{T}^{C M}\right)>E\left(\pi_{T}^{C P}\right)$.

Thus, Corollary 4 is proved. 